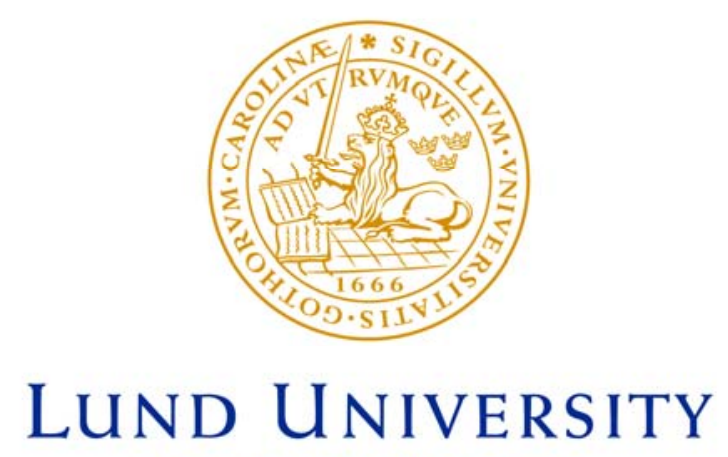

Faculty of Medicine

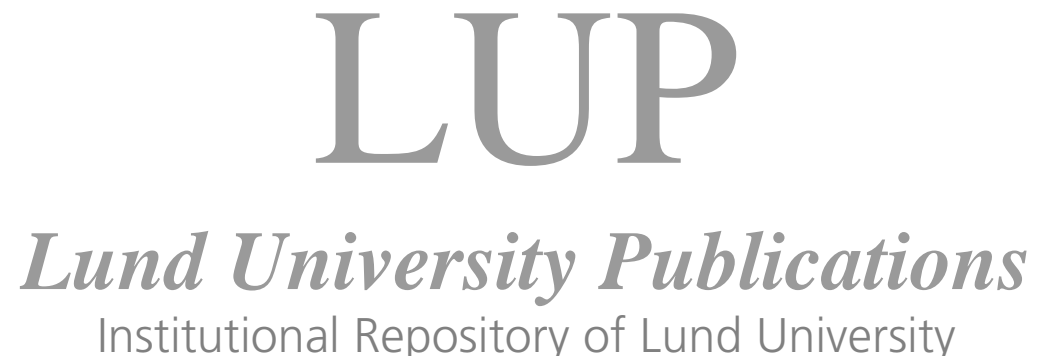

Institutional Repository of Lund University

This is an author produced version of a paper published in Occupational and environmental medicine. This paper has been peer-reviewed but does not include the final publisher proof-corrections or journal pagination.

Citation for the published paper:

Axmon, Anna; Rylander, Lars

Birth weight and fetal growth in infants born to female hairdressers and their sisters.

in Occupational and environmental medicine, 2008, Issue: 3

http://dx.doi.org/10.1136/oem.2008.039784

Access to the published version may

require journal subscription.

Published with permission from:

BMJ Publishing Group 


\title{
Birth weight and fetal growth in infants born to female hairdressers and their sisters
}

\author{
Anna Axmon \\ Division of Occupational and Environmental Medicine, Lund University, University Hospital, \\ SE-221 85 Lund. E-mail anna.axmon@med.lu.se. Phone +46-46-173960. Fax +46-46- \\ 173669. \\ Lars Rylander \\ Division of Occupational and Environmental Medicine, Lund University, University Hospital, \\ SE-221 85 Lund. E-mail lars.rylander@med.lu.se. Phone +46-46-177287. Fax +46-46- \\ 173669.
}

Key words: Occupational exposure, pregnancy, fetal growth

\begin{abstract}
Objectives: To investigate birth weight and fetal growth in female hairdressers, while controlling for intergenerational effects and effects related to childhood exposures.

Methods: A cohort of women who had attended vocational schools for hairdressers were compared to their sisters with respect to birth weight and fetal growth (measured as small or large for gestational age, SGA and LGA, respectively) in their infants. In total, 6223 infants born to 3137 hairdressers and 8388 infants born to 3952 hairdresser's sisters were studied.

Results: Among the infants born to the hairdresser's sisters, the distribution of birth weights were wider than that among the infants born to the hairdressers. This was also reflected in that hairdresser cohort affiliation tended to be protective against both SGA (odds ratio 0.80; 95\% confidence interval 0.49-1.31) and LGA (0.77; 0.54-1.09). For LGA, this effect was even more pronounced among women who had actually worked as a hairdresser during at least one pregnancy $(0.60 ; 0.39-0.92)$. The infants born to these women also had a significantly lower mean birth weight (3387 g vs $3419 \mathrm{~g}$; $\mathrm{p}=0.033$ ).

Conclusions: The results from the present study suggest that infants born to hairdressers have a decreased risk of being LGA. This is most likely not caused by a shift in birth weight distribution or abnormal glucose metabolism.
\end{abstract}

Main message: Contrary to previous studies, no increased risk of low birth weight or growth retardation was found among infants born to hairdressers after taking intergenerational effects and effects of childhood exposure into consideration. 


\section{INTRODUCTION}

In Sweden, a large majority (about 80\%) of hairdressers are women [1,2]. Moreover, among women employed as hairdressers, the mean age is relatively low (36 years) [2], implying that a large percentage is of reproductive age. To work as a hairdresser generally involves daily exposure to a line of chemicals $[3,4]$, some of which have been found to be hazardous to reproductive health in both animals and humans. These include, but are not restricted to, organic solvents [5,6], nitrosoamines [7], and phthalates [8-10]. However, chemical exposure is not the only aspect of hairdresser work that may be unsafe. A large fraction of the Swedish female hairdressers are self-employed [11,12], which is frequently associated with working more hours than what is considered full-time. Long working hours have been suggested to place both the pregnancy and fetus at risk [13-15], as have prolonged standing [13-17], another factor associated with working as a hairdresser.

Cohort studies focused on female hairdressers have indicated small or non-existent effects on fertility, measured as time to pregnancy [11] and subfecundity [18,19]. However, the fetus seem to be more vulnerable than the mother, as indicated by increased risks of undesired pregnancy outcomes, such as low birth weight (<2500 g; LBW) [19-21], intrauterine growth retardation (measured as small for gestational age; SGA) [20,21], and congenital malformations $[19,20]$. Nevertheless, when studying reproductive health in occupational cohorts, it cannot be ruled out that at least part of the effect is due to genetic factors, or related to childhood exposures. For instance, intergenerational effects have been found for birth weight [22-24], fetal growth [25-27], and preterm birth [26]. Examples of the influence of the woman's childhood environment include associations between her social class during childhood and the birth weight of her children [28], as well as exposure to persistent organochlorine compounds in utero and during childhood and the subsequent birth weight of children of the next generation [29].

In Sweden, hairdresser training is organized by vocational schools which may be attended after having finished the obligatory first nine school years. Traditionally, the hairdresser education has been very sought after, and consequently a very high average grade has been required to be admitted to these schools. Indeed, at many schools future hairdressers have traditionally had to have higher grades than students applying to those educations which are required to later on be able to study e.g. medicine or law. Thus, Swedish hairdressers constitute an occupational group which is not comparable to any other, with students with high elementary school grades, but no academic studies. Consequently, proper comparison groups for epidemiological studies are hard to find.

In the present study, we compared birth weight among infants born to female hairdressers to that of infants born to hairdressers' sisters, thus controlling for potential effects of genetics and childhood environment.

\section{MATERIALS AND METHODS}

\section{Study cohorts and data collection}

In 1996, a cohort of women who had graduated from any of the 29 Swedish vocational schools for hairdressers between 1970 and 1995, and who were born in 1946 or later, was established [30]. In total, the cohort comprised 7202 women with median age 31 years in 1996. To identify the parents, and subsequently the sisters, of the hairdressers, the cohort was matched to registers at the National Tax Board of Sweden.

The registers at the National Tax Board have been computerized since 1991. In these registers, all Swedish citizens are identified by a unique 10-digit personal identification code, which also provides information on the individual's date of birth and gender. Moreover, for each individual, information is available on the personal identification code of both parents, as well as that of the children of the individual. Thus, by using a person's personal identification 
code, his/her parents may be identified, and subsequently via the parents' personal identification codes, the siblings and half-siblings of the index person. However, identification of siblings may be done allowing for a few exceptions: Firstly, if the index person has immigrated to Sweden without his/her parents, information on the parents is obviously not recorded at the National Tax Board. Second, when registers were computerized in 1991, information was not added on persons no longer residing in Sweden. Moreover, in 2006, the registers were purged in the sense that the link between parent and child was deleted for individuals who were deceased or emigrated as of November 2005. Therefore, siblings may not be identified to index persons whose parents were deceased or emigrated as of that date. By using the registers at the National Tax Board, both parents were identified and alive as of November 2005 for 4407 (61\%) of the hairdressers, and such information was available regarding only one parent for 1944 (27\%; 434 fathers and 1510 mothers) women (Figure 1).

A second linkage was then performed to identify the children to the hairdressers' mothers and hairdressers' fathers, i.e. the siblings and half-siblings of the hairdressers. Hairdressers without a sister were excluded, as were those whose sister was also a hairdresser (Figure 1). For those hairdressers where information was available on both parents, there were no half-sisters (i.e. only one parent in common). In order to obtain information on the pregnancy outcome among the hairdressers and their sisters, the cohort was linked to the Medical Birth Registry (MBR).

The MBR is based on copies of record forms for maternity health care, the delivery, and the pediatric examination of the newborn, and includes almost every infant born in Sweden since 1973 [31]. From the MBR, information is available on infant related variables, such as birth weight and height, and indicators suggesting that the intra-uterine growth of the infant deviates from the standard (measured as small for gestational age [SGA] and large for gestational age [LGA] [32]). However, some variables, such as maternal smoking in early pregnancy and maternal occupation, were not included until 1982. Moreover, factors relating to the mother, such as her pre-pregnancy height and weight, is also included. For ethical reasons, information retrieved from the MBR and used in epidemiological studies may not be known in such a way that single individuals may be identified. Thus, each sibling group was given an identifying number, and each child in each sibling group was identified as either a hairdresser infant or a sister infant. As a result, if a hairdresser had two sisters which were twins, their children could not be ascribed to the correct mother. Thus, these were excluded from the analyses (78 women). However, of the 39 hairdressers whose sisters were twins, 22 had at least one more sister and was therefore included in the analyses.

In all, 6568 infants born to 3205 hairdressers and 8782 infants born to 4018 hairdresser's sisters were identified. However, 345 hairdresser infants and 394 sister infants were excluded for various reasons (see Figure 1), leaving the final dataset to contain 6223 infants born to 3137 hairdressers and 8388 infants born to 3952 hairdresser sisters. Moreover, 5134 infants to excluded hairdressers were identified (see also Excluded women below).

Among the included women, there were no major differences between the hairdressers and their sisters with respect to year of birth, age at delivery or smoking habits (Table 1). Restrictions to hairdressers who, according to the MBR, had worked as hairdressers during at least one pregnancy, pregnancies that occurred after 1982, did not have any major impact on the distribution of these factors (data not shown).

The study was performed in accordance with the Declaration of Helsinki and approved by The Lund University Ethic's Committee. All participants provided written informed consents. 
Figure 1. Inclusion of Swedish female hairdressers and their sisters into a study regarding occupational exposure and infant birth weight.

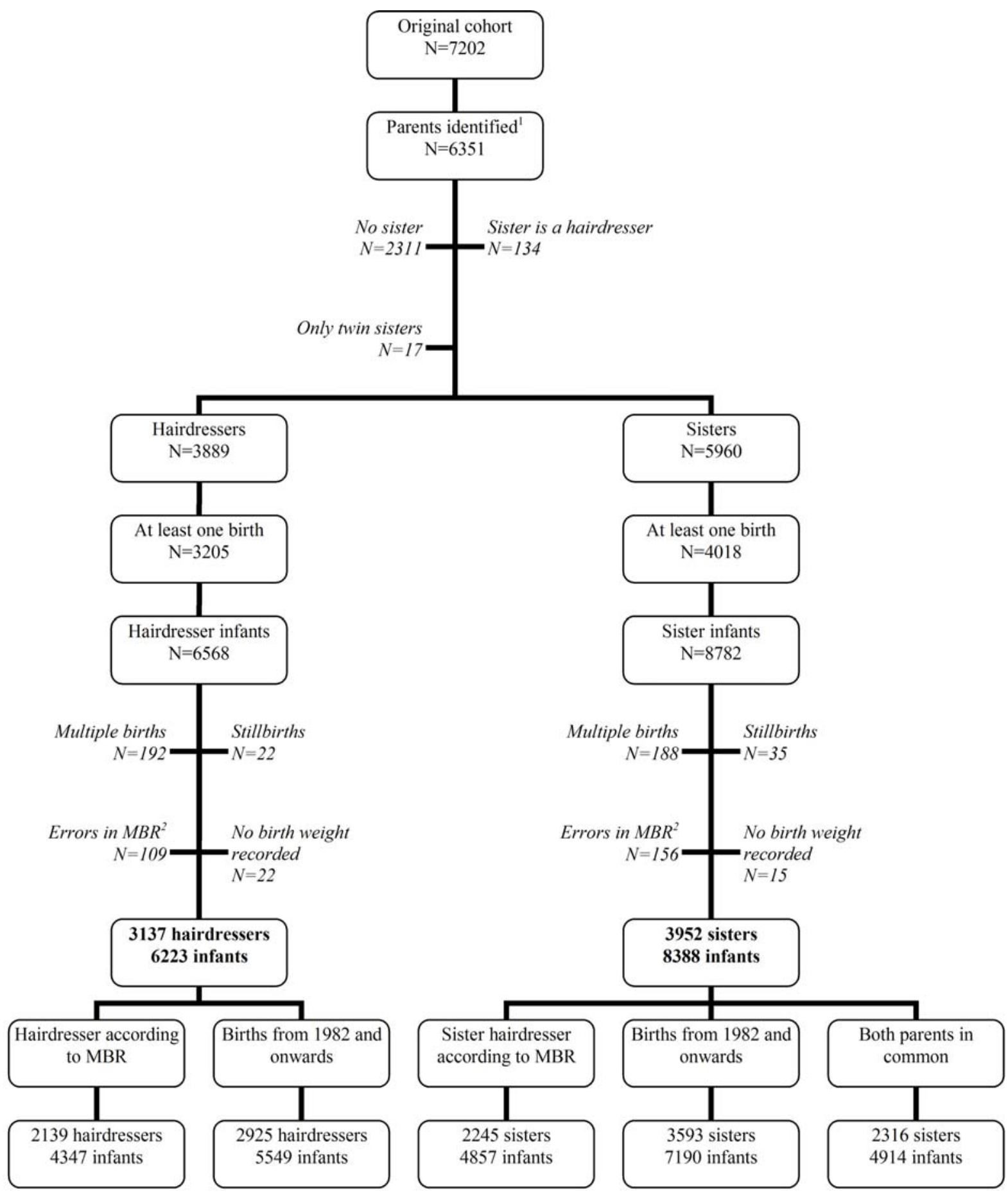

${ }^{1}$ Whereof both parents were identified for 4407 hairdressers, only the mother for 1510 hairdressers, and only the father for 434 hairdressers.

${ }^{2}$ Two or more children of the same woman were assigned the same parity. 
Table 1. Descriptive data on 4347 pregnancies from 3137 hairdressers and 4857 pregnancies from 3952 hairdresser's sisters. Please note that due to missing data all numbers do not add up to $100 \%$.

\begin{tabular}{lll}
\hline & Hairdressers & Sisters \\
\hline Observational unit = woman & & \\
Year of birth (mean, 95\% range) & $1965(1951,1975)$ & $1965(1948,1978)$ \\
Height (mean, 95\% range) & $166(155,177)$ & $166(154,178)$ \\
Non-smoker at all pregnancies (n, \%) & $1975(79)$ & $2193(76)$ \\
Changed smoking habits between pregnancies (n, \%) & $263(8)$ & $380(10)$ \\
Observational unit = pregnancy & & \\
Gestational length (mean, 95\% range) & $39(23,45)$ & $39(22,44)$ \\
Maternal age (mean, 95\% range) & $28(15,46)$ & $28(16,44)$ \\
First parity (n, \%) & $2987(48)$ & $3690(44)$ \\
Maternal weight (kg; mean, 95\% range) & $66(50-95)$ & $66(49-97)$ \\
Maternal weight increase since last pregnancy (n, \%) & $681(21)$ & $805(23)$ \\
BMI & & \\
$\quad<20$ & $319(10)$ & $365(10)$ \\
$\quad 20-25$ & $1976(61)$ & $2066(59)$ \\
$\quad 25-30$ & $682(21)$ & $781(22)$ \\
$\quad>30$ & $237(7)$ & $279(8)$ \\
Maternal BMI increase since last pregnancy (n, \%) & $199(6)$ & $257(7)$ \\
Boy (n, \%) & $3222(52)$ & $4358(52)$ \\
Non-smoking mother (n, \%) & 1 (1, & $5233(78)$ \\
\hline
\end{tabular}

${ }^{1}$ Based on pregnancies from 1982 and onwards.

${ }^{2}$ BMI categorized as low, normal, overweight and obese.

\section{Excluded women}

Due to missing information in the registries at the National Tax Board, and exclusion of hairdressers who had no sisters, the hairdresser used in the analyses represented $54 \%$ of the original cohort. However, the main reason for exclusion (32\% of the total cohort) was not having a sister. When introducing restrictions as to year of birth, the numbers were similar when including only women born from 1960 and onwards (59\% included, 33\% missing a sister) or women born from 1970 and onwards (60\% included, 35\% missing a sister). Hairdressers who were excluded from the study for various reasons were slightly older than those included (median age 43 vs. 40 years), and had consequently graduated from hairdresser school somewhat earlier (median graduation year 1985 vs. 1987).

Comparisons between included and excluded women were done not imposing the restrictions described above (e.g. excluding multiple births and stillbirths). The analyses showed no difference among the infants born to the excluded and included hairdressers with respect to birth weight (median $3510 \mathrm{~g}$ in both groups [mean $3480 \mathrm{~g}$ among excluded and $3485 \mathrm{~g}$ among included]), birth length (median and mean $50 \mathrm{~cm}$ in both groups), or gestational length (median 40 weeks and mean 39 weeks in both groups). Moreover, the fraction of male infants (51.8\% vs. $51.9 \%)$ and non-smoking mothers (80.8\% vs. $79.9 \%)$ were similar among excluded and included hairdressers. The differences in percentage of SGA (3.4\% vs. $2.8 \%$ ) or LGA (2.6\% vs. 3.2\%) were small.

\section{Statistics}

To estimate the difference in birth weight between infants born to hairdressers and their sisters, while taking into account the dependence between sisters as well as that between subsequent pregnancies for the same woman, mixed models based on the restricted maximum 
likelihood (REML) were used (SPSS version 15.0). The mixed model is an expansion of the general linear model, and estimates overall effects (fixed effects) as well as effects that occur within groups of observations (random effects). Moreover, it allows for repeated measures. In the analyses in the present study, cohort affiliation (hairdresser or sister), as well as all potential confounders, were assessed as fixed effects. Each sibling group was designated a unique identification number, and this number was included in the model as a random factor. The essence of this is, that each sibling group is presumed to have an underlying probability of the outcome (e.g. giving birth to an SGA-infant). Although this probability is not estimated by the model, it is taken into consideration when the overall effect estimates are determined. Parity was used to determine repeated measures. To determine the covariance structure for the repeated measures, the crude model comparing hairdressers to sisters was used. The covariance structure determines the dependency between subsequent pregnancies for the same woman. The Schwartz Bayesian Information Criterion (IC) was used as guidance in the choice of covariance structure. The ARMA(1,1) model had the lowest IC and was also considered as a plausible structure in this situation. For the random factor (sibling group), variance components covariance structure was used.

In the analyses of SGA, LGA and LBW, we calculated the odds ratio (OR) of exposure among those with the respective outcome. Since the formula for this is identical to that estimating the OR of outcome among those exposed, the calculated OR may be interpreted either way. The rationale for using this unusual method of OR calculation was to be able to account for the matching of hairdressers to their sisters. Thus, conditional logistic regression (Egret 2.0) was used to estimate the ORs and their 95\% confidence intervals (CIs). Since this procedure does not take into account repeated measures, each woman was allowed to contribute with only one pregnancy to the analyses. For women with multiple pregnancies, her last recorded pregnancy was chosen in order to get the subset of pregnancies after 1982 as large as possible (see also below).

Subgroup analyses were run using only those sisters who were identified as having both parents in common with the hairdresser of that sibling group, and for the group of hairdressers who were working as a hairdresser according to the MBR. Note, that since only one of the pregnancies needed to be as a hairdresser, pregnancies prior to 1982 could also be included. Finally, since smoking and maternal height was not recorded in the MBR until 1982, subgroup analyses were also performed for births occurring 1982 or later.

Maternal smoking (non-smoker, 1-9 cigarettes/day, 10 or more cigarettes/day), maternal age, maternal height, and infant gender were considered as potential confounders and thus included in multivariate models. Moreover, parity was included in those models which were based on only one pregnancy per woman. Due to poor quality of the data concerning pre-pregnancy maternal weight in the MBR, the main analyses were not adjusted for BMI.

\section{RESULTS}

A total of 14611 infants born to 7089 women were included in the birth weight analysis, whereas 3137 hairdressers and 3952 sisters were included in the analyses regarding SGA, LGA and LBW, providing information on one child each. The majority of the pregnancies (54\% for the hairdressers and $49 \%$ for the sisters) in the latter analyses were of parity two, with the rest roughly equally distributed among first parity births and births of parity higher than two. 
Figure 2. Birth weight distribution among 6223 infants born to Swedish female hairdressers (grey bars) and 8388 infants born to the hairdresser's sisters (white bars).

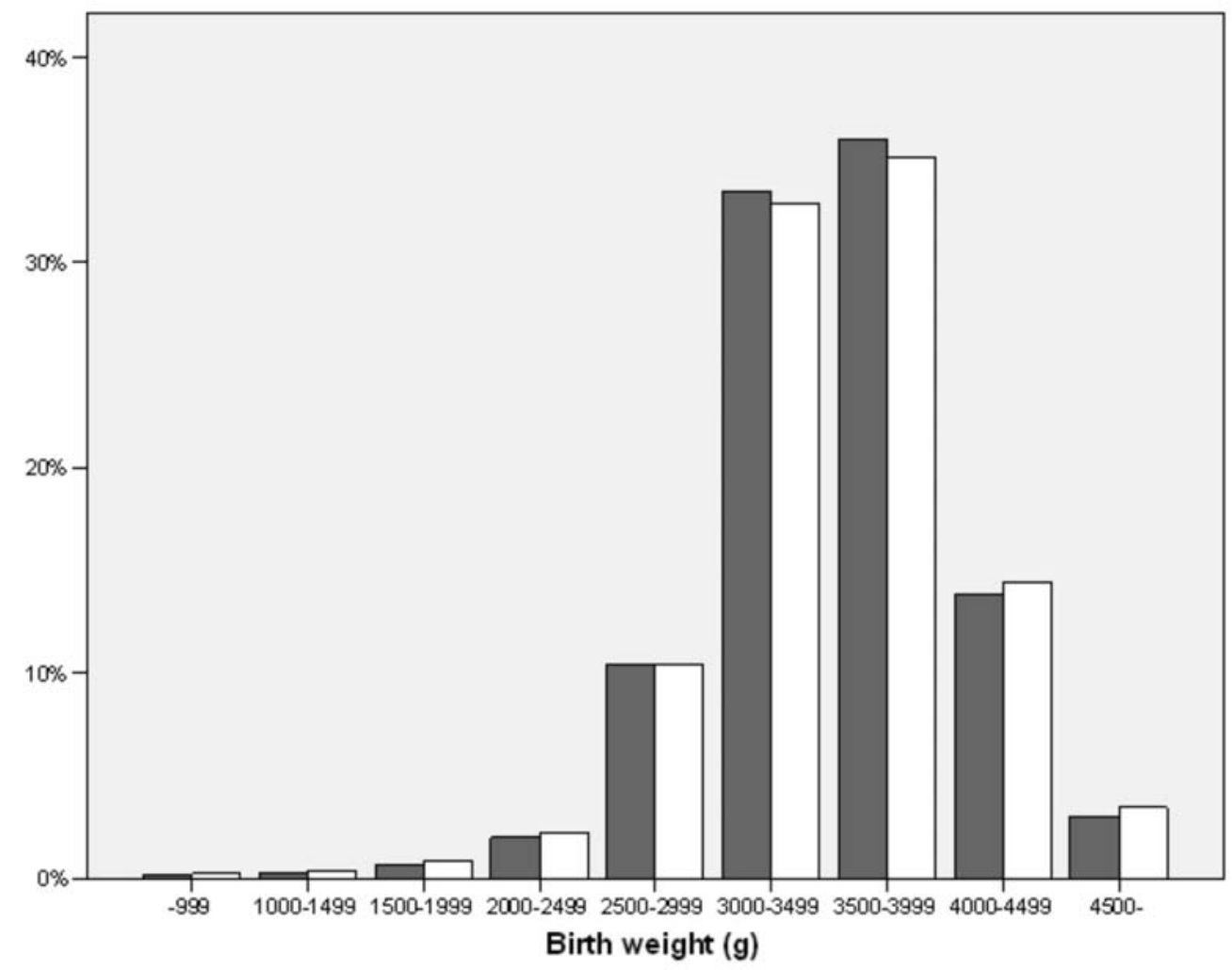

The birth weight distribution differed between the hairdressers and their sisters in that the birth weights of the hairdresser infants were more centered around the mean (Figure 2). This was also reflected in that hairdresser cohort affiliation was protective against both SGA and LGA (Table 2). Similar effects were found across all subgroups, although the effect was consistently statistically significant only for LGA among the subgroup of hairdressers who had worked as a hairdresser during at least one pregnancy. When restricting the analyses to women for whom BMI was available, and adjusting for gender, maternal age, parity, maternal height and smoking, but not for BMI, the OR for LGA among infants born to women who had at least one pregnancy as a hairdresser was 0.53 (95\% CI 0.30, 0.92). When including BMI in this model, the resulting OR was $0.54(0.31,0.95)$.

Although the crude mean birth weight was the same for both cohorts (3515 g), the hairdresser infants had a marginally lower mean birth weight in the adjusted analyses. This was most marked when restricting the analyses to women who had actually worked as a hairdresser during at least one pregnancy, and their sisters (Table 3). 


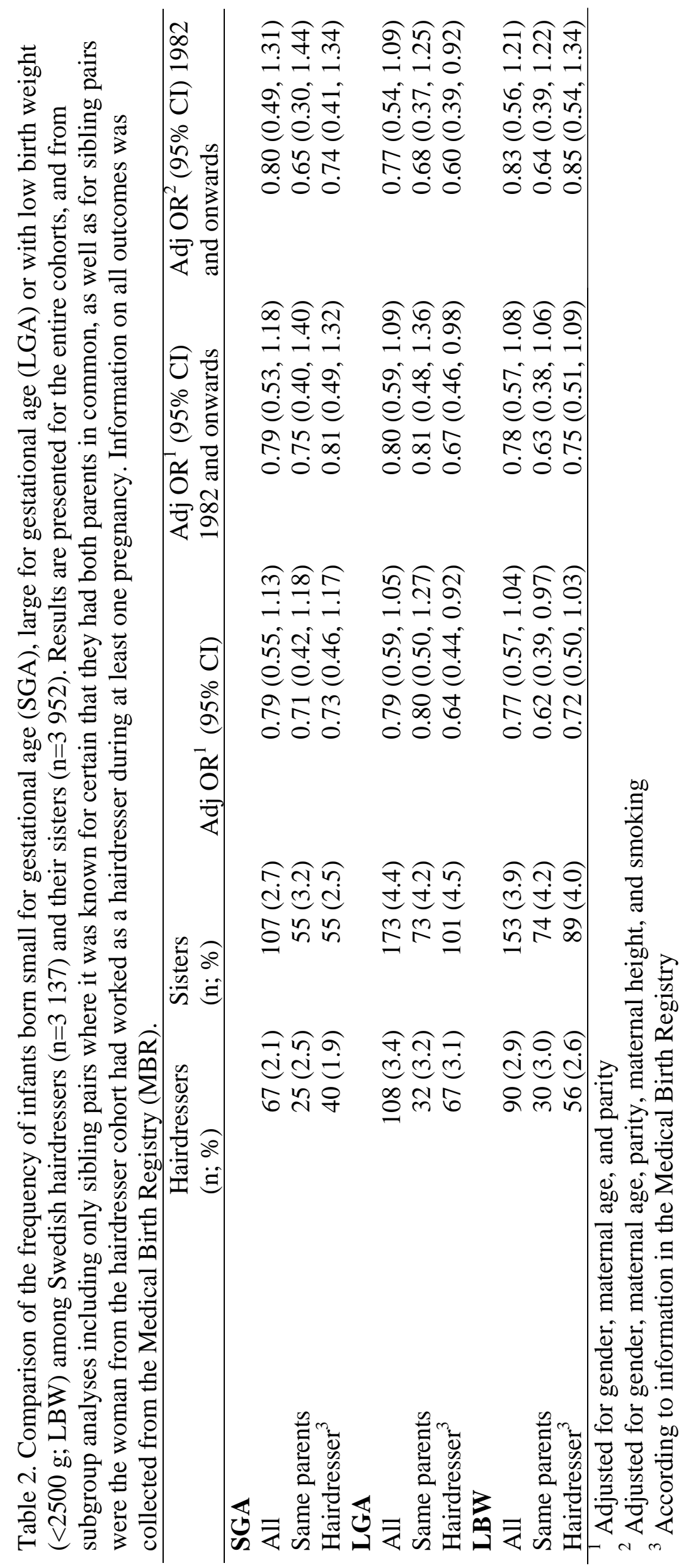




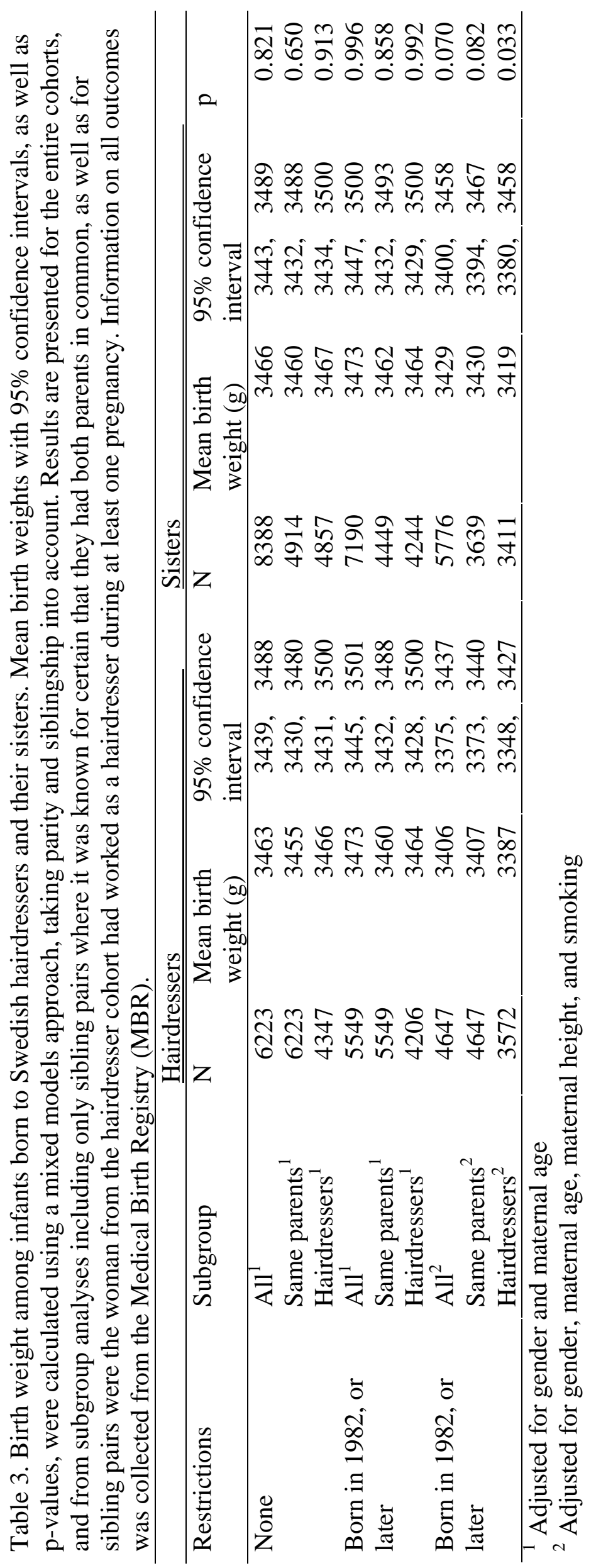




\section{DISCUSSION}

The results from the present study suggest a protective effect of giving birth to an LGA infant among the hairdressers compared to their sisters. No consistent effects were found with respect to SGA and birth weight.

A major strength of the present study is the use of the hairdresser's sisters as a control cohort. Intergenerational effects [22-27] and influence of childhood environment [28,29] have been found for several reproductive outcomes. Thus, it cannot be ruled out that epidemiological studies comparing an occupational cohort to controls from the general population are affected by genetic and environmental factors other than those under study. In the present study, such effects are eliminated by matching each hairdresser to her sisters. To establish a control cohort comprising sisters of course demands accessibility to a Multi Generation Register. In Sweden, we do have this opportunity.

Another strength of the study is the possibility to identify women who actually worked as a hairdresser by using information on the mothers occupation in the MBR. This information in prospectively collected during early pregnancy (normally around gestational week 10-14). The effect of hairdresser cohort affiliation on SGA as well as LGA was strengthened when restricting the exposed cohort to only those women who had actually worked as a hairdresser during at least one pregnancy, suggesting that it indeed is the hairdresser work that causes the effect. One must, however, take into consideration that information on maternal occupation is entered into the MBR as a string variable, and that e.g. spelling errors may have lead to misclassification of jobs in the present study. Nevertheless, we believe that women who were classified as hairdressers most likely were such, and thus a possible misclassification would only result in failure to include all hairdressers. Hence, the resulting effect should be limited to wider confidence intervals for the outcomes investigated.

Even if matching the hairdressers to their sisters eliminates disturbances from genetic effects and childhood exposure, the results could still be distorted if the hairdressers' sisters were prone to occupations which carried other reproductive hazards. However, through Statistics Sweden (http://www.scb.se) we identified the most common professions in Swedish women, and compared the frequencies of these professions in the Swedish female population to those in the hairdresser's sisters cohort. Considering the various differences in this comparison, e.g. different time windows, poor quality of information from the MBR, and multiple pregnancies for some women, the agreement between the sister cohort and the Swedish female population was surprisingly high (data not shown). Hence, the risk that specific hazardous occupations should be over represented in the sister cohort is minor.

When identifying the parents of the hairdressers, it was only possible to find both mother and father for $61 \%$ of the women. The main reason for not being able to identify both parents was that one or both parents were deceased or had emigrated. Nevertheless, for a considerable fraction of the sibling groups it is unknown if the siblings share both parents or only one. However, among those hairdressers were both parents were identified, there were no women who had sisters with only one parent in common. Hence, it is likely that the majority of those sibling groups that were matched on only one parent indeed shared both parents. This conclusion is also supported by the fact that similar results were obtained in the analyses of the entire cohorts as when restricting the analyses to women who were known to have both parents in common with the index hairdresser.

In Sweden, admittance to hairdresser vocational schools traditionally requires a high average grade from elementary school. Thus, other non-academic occupational groups may not be a suitable comparison in studies of health among Swedish hairdressers. On the other hand, hairdresser is not an academic occupation, and thus academic occupational groups may not be a proper comparison group either. High socioeconomic status, which is often the result 
of an academic education, has been associated with a healthy lifestyle [33-36]. However, there is probably no reason to believe that high grades at the age of 15 would cause a woman to have a healthier life style than a sibling who grew up in the same family. In support of this, it has been found that at 18 years of age, alcohol intake in women was associated with alcohol intake among their fathers [37], and that still at age 33, men and women with overweight parents have increased risk of obesity [38]. Moreover, factors known to be indicators of socioeconomic status, such as smoking and body weight, were similar among the hairdressers and their sisters. Thus, the results are most likely not due to a difference in lifestyle between hairdressers and their sisters.

Due to the specific traits of the Swedish hairdressers, comparison with studies performed on hairdressers in other countries, where the educational background of the hairdresser differ from the Swedish, may not be straightforward. However, by using the hairdresser's sisters as a comparison cohort in the present study, we believe that we have eliminated this problem, and that our results may be applicable also in other settings.

There were no data available on whether the hairdressers continued to work throughout pregnancy. Thus, even when restricting the analyses to sister pairs where the sister from the hairdresser cohort was actually working as a hairdresser when she registered at the maternity ward, the hairdresser cohort may be diluted with women who were not exposed. Considering that all findings were stronger in the analyses of the restricted cohorts, such dilution of the hairdresser cohort would probably have lead to a bias towards the null.

Pregnancy interval is known to be associated with pregnancy outcome [39-43]. Thus, if the inter-pregnancy interval differed between the two cohorts, this may have affected the results. However, subgroup analyses using only births of parity one, found similar results as when including all births (data not shown).

Previous studies on SGA in hairdressers are few, with some suggesting an increased risk of SGA [20,21] and others not finding any effect at all [44]. Regarding low birth weight, previous studies in which an increased risk has been indicated have failed to reach statistical significance for this [19-21,45]. Thus, for low birth weight and SGA, the results from the present study is not contradictory to what has already been seen in other studies.

With respect to LGA, this is an outcome which has not been investigated previously among hairdressers. Several weight related factors, such as being overweight or obese [46], having an excessive gestational weight gain [47], or an increase in BMI from normal to obese between pregnancies [46], have been found to increase the risk of giving birth to an LGA infant. Thus, if the hairdressers were leaner, or had less weight increase during and between pregnancies, than their sisters, the protective effect regarding LGA could have been explained by this. The MBR contains very poor information on gestational weight gain, and in the present study the records of maternal pre-pregnancy weight was only available for $75 \%$ of the hairdressers and $70 \%$ of the sisters for whom height was available had provided a weight measure. Thus, we did not adjust the main analyses for pre-pregnancy BMI or gestational weight gain. Among those women where a BMI was obtainable, the hairdressers had marginally lower BMI, and were slightly more likely to decrease their BMI between pregnancies. Nevertheless, adjusting for BMI in the analysis where the impact of hairdresser cohort affiliation was most prominent (among women with at least one pregnancy as a hairdresser), inclusion of BMI in the multivariate model did not change the effect estimate. Hence, failure to include BMI as a confounder is an unlikely explanation for the findings in the present study.

Even though maternal anthropometry is important, the most significant risk factor for fetal overgrowth is abnormalities of the glucose metabolism [48-50]. Thus, if the prevalence of such disorders was higher among the hairdressers' sisters than among the hairdressers, this could explain the results found in the present study. We did not have any information on 
diabetes or abnormal metabolism for the women in the study. However, disturbances in the glucose metabolism, including diabetes, is strongly affected by hereditary factors, which the study was designed to eliminate. Thus, it is not likely that the decreased risk of LGA in the present study is due to diabetes or abnormal glucose metabolism.

In conclusion, the present study indicates that infants born to hairdressers are less likely to be LGA than those infants born to hairdresser's sisters. The effect was most obvious among those women who had actually worked as a hairdresser during at least one pregnancy rather than only having formal training as a hairdresser. The results are most likely not the result of dissimilar weight distributions in the studied cohorts, or different prevalences of abnormal glucose metabolism. However, the results are unexpected since the previous research suggests hairdresser work to be hazardous rather than protective. It should be pointed out that LGA among infants born to hairdressers has not been investigated previously, and until the results from the present study are supported by other studies, they should be interpreted cautiously.

\section{ACKNOWLEDGEMENTS}

The present study was initiated by Professor Lars Hagmar, who sadly passed away in 2006. The authors are grateful to Professor Ulf Strömberg for discussions regarding the statistical analyses.

FINANCIAL SUPPORT

The Swedish council for working life and social research.

\section{REFERENCES}

1. SCB. Service professions. Statistics Sweden, 2003.

2. SCB. The occupational structure in Sweden 2005 - Occupational statistics based on the Swedish occupational register. In: Jansson K, ed. Statistiska meddelanden Statistics Sweden, 2007.

3. Kersemaekers WM, Roeleveld N, Zielhuis GA. Reproductive disorders due to chemical exposure among hairdressers. Scand J Work Environ Health 1995;21:32534.

4. Labreche F, Forest J, Trottier M, et al. Characterization of chemical exposures in hairdressing salons. Appl Occup Environ Hyg 2003;18:1014-21.

5. Huel G, Mergler D, Bowler R. Evidence for adverse reproductive outcomes among women microelectronic assembly workers. Br J Ind Med 1990;47:400-4.

6. Lipscomb JA, Fenster L, Wrensch M, et al. Pregnancy outcomes in women potentially exposed to occupational solvents and women working in the electronics industry. $J$ Occup Med 1991;33:597-604.

7. Preston-Martin S, Yu MC, Benton B, et al. N-Nitroso compounds and childhood brain tumors: a case-control study. Cancer Res 1982;42:5240-5.

8. Latini G, De Felice C, Presta G, et al. In utero exposure to di-(2-ethylhexyl)phthalate and duration of human pregnancy. Environ Health Perspect 2003;111:1783-5.

9. Swan SH, Main KM, Liu F, et al. Decrease in anogenital distance among male infants with prenatal phthalate exposure. Environ Health Perspect 2005;113:1056-61.

10. Main KM, Mortensen GK, Kaleva MM, et al. Human breast milk contamination with phthalates and alterations of endogenous reproductive hormones in infants three months of age. Environ Health Perspect 2006;114:270-6.

11. Axmon A, Rylander L, Lillienberg L, et al. Fertility among female hairdressers. Scand $J$ Work Environ Health 2006;32:51-60.

12. SCB. Other service activities 2002. In: öberg S, ed. Statistiska meddelanden Statistics Sweden, 2004. 
13. Bonzini M, Coggon D, Palmer KT. Risk of prematurity, low birthweight and preeclampsia in relation to working hours and physical activities: a systematic review. Occup Environ Med 2007;64:228-43.

14. Seguin RE. Pregnancy and the working woman: a review. J Ark Med Soc 1998;95:115-8.

15. Berkowitz GS, Papiernik E. Working conditions, maternity legislation, and preterm birth. Semin Perinatol 1995;19:272-8.

16. Mozurkewich EL, Luke B, Avni M, et al. Working conditions and adverse pregnancy outcome: a meta-analysis. Obstet Gynecol 2000;95:623-35.

17. McCulloch J. Health risks associated with prolonged standing. Work 2002;19:201-5.

18. Hougaard KS, Hannerz H, Bonde JP, et al. The risk of infertility among hairdressers. Five-year follow-up of female hairdressers in a Danish national registry. Hum Reprod 2006;21:3122-6.

19. Kersemaekers WM, Roeleveld N, Zielhuis GA. Reproductive disorders among hairdressers. Epidemiology 1997;8:396-401.

20. Rylander L, Axmon A, Toren K, et al. Reproductive outcome among female hairdressers. Occup Environ Med 2002;59:517-22.

21. Rylander L, Kallen B. Reproductive outcomes among hairdressers. Scand J Work Environ Health 2005;31:212-7.

22. Lunde A, Melve KK, Gjessing HK, et al. Genetic and environmental influences on birth weight, birth length, head circumference, and gestational age by use of population-based parent-offspring data. Am J Epidemiol 2007;165:734-41.

23. Collins JW, Jr., David RJ, Prachand NG, et al. Low birth weight across generations. Matern Child Health J 2003;7:229-37.

24. Hyppönen E, Power C, Smith GD. Parental growth at different life stages and offspring birthweight: an intergenerational cohort study. Paediatr Perinat Epidemiol 2004;18:168-77.

25. Selling KE, Carstensen J, Finnstrom O, et al. Intergenerational effects of preterm birth and reduced intrauterine growth: a population-based study of Swedish motheroffspring pairs. Bjog 2006;113:430-40.

26. Tocharoen A, Thompson S, Addy C, et al. Intergenerational and environmental factors influencing pregnancy outcomes. Ann Epidemiol 2000;10:475-476.

27. Ahlsson F, Gustafsson J, Tuvemo T, et al. Females born large for gestational age have a doubled risk of giving birth to large for gestational age infants. Acta Paediatr 2007;96:358-62.

28. Gisselmann MD. The influence of maternal childhood and adulthood social class on the health of the infant. Soc Sci Med 2006;63:1023-33.

29. Rylander L, Stromberg U, Hagmar L. Lowered birth weight among infants born to women with a high intake of fish contaminated with persistent organochlorine compounds. Chemosphere 2000;40:1255-62.

30. Albin M, Rylander L, Mikoczy Z, et al. Incidence of asthma in female Swedish hairdressers. Occup Environ Med 2002;59:119-23.

31. Cnattingius S, Ericson A, Gunnarskog J, et al. A quality study of a medical birth registry. Scand J Soc Med 1990;18:143-8.

32. Kallen B. A birth weight for gestational age standard based on data in the Swedish Medical Birth Registry, 1985-1989. Eur J Epidemiol 1995;11:601-6.

33. Carstairs V, Morris R. Deprivation: explaining differences in mortality between Scotland and England and Wales. Bmj 1989;299:886-9.

34. Mackenbach JP. Socioeconomic inequalities in health in The Netherlands: impact of a five year research programme. Bmj 1994;309:1487-91. 
35. Kennedy BP, Kawachi I, Prothrow-Stith D. Income distribution and mortality: cross sectional ecological study of the Robin Hood index in the United States. Bmj 1996;312:1004-7.

36. Smith GD, Egger M. Socioeconomic differences in mortality in Britain and the United States. Am J Public Health 1992;82:1079-81.

37. Burke V, Beilin LJ, Dunbar D. Family lifestyle and parental body mass index as predictors of body mass index in Australian children: a longitudinal study. Int J Obes Relat Metab Disord 2001;25:147-57.

38. Lake JK, Power C, Cole TJ. Child to adult body mass index in the 1958 British birth cohort: associations with parental obesity. Arch Dis Child 1997;77:376-81.

39. Cecatti JG, Correa-Silva EP, Milanez H, et al. The associations between interpregnancy interval and maternal and neonatal outcomes in Brazil. Matern Child Health J 2008;12:275-81.

40. Zhu BP, Rolfs RT, Nangle BE, et al. Effect of the interval between pregnancies on perinatal outcomes. $N$ Engl J Med 1999;340:589-94.

41. Rawlings JS, Rawlings VB, Read JA. Prevalence of low birth weight and preterm delivery in relation to the interval between pregnancies among white and black women. N Engl J Med 1995;332:69-74.

42. Adams MM, Delaney KM, Stupp PW, et al. The relationship of interpregnancy interval to infant birthweight and length of gestation among low-risk women, Georgia. Paediatr Perinat Epidemiol 1997;11 Suppl 1:48-62.

43. Klerman LV, Cliver SP, Goldenberg RL. The impact of short interpregnancy intervals on pregnancy outcomes in a low-income population. Am J Public Health 1998;88:1182-5.

44. Zhu JL, Vestergaard M, Hjollund NH, et al. Pregnancy outcomes among female hairdressers who participated in the Danish National Birth Cohort. Scand J Work Environ Health 2006;32:61-6.

45. McDonald AD, McDonald JC, Armstrong B, et al. Occupation and pregnancy outcome. Br J Ind Med 1987;44:521-6.

46. Getahun D, Ananth CV, Peltier MR, et al. Changes in prepregnancy body mass index between the first and second pregnancies and risk of large-for-gestational-age birth. Am J Obstet Gynecol 2007;196:530 e1-8.

47. Cedergren M. Effects of gestational weight gain and body mass index on obstetric outcome in Sweden. Int J Gynaecol Obstet 2006;93:269-74.

48. Mello G, Parretti E, Mecacci F, et al. Risk factors for fetal macrosomia: the importance of a positive oral glucose challenge test. Eur J Endocrinol 1997;137:2733.

49. Leikin EL, Jenkins JH, Pomerantz GA, et al. Abnormal glucose screening tests in pregnancy: a risk factor for fetal macrosomia. Obstet Gynecol 1987;69:570-3.

50. Lindsay MK, Graves W, Klein L. The relationship of one abnormal glucose tolerance test value and pregnancy complications. Obstet Gynecol 1989;73:103-6. 